\section{Retrieval of proximally migrated plastic biliary stents using a metal stent}

The use of endoscopic stents is common in the treatment of biliary tract stenosis. However, the proximal migration of these stents occasionally results in complications that are difficult to manage [1]. Various techniques for stent retrieval have been described, including the use of Dormia baskets, rat-tooth forceps, a balloon, or Soehendra-type stent retrievers [2]. This paper presents a new technique for the retrieval of proximally migrated plastic biliary stents.

A 77-year-old woman with mental retardation since childhood was admitted to hospital with symptoms of jaundice associated with the dilation of the secondary biliary tract and a neoplastic lesion in the head of pancreas, rejected for surgery. Endoscopic retrograde cholangiopancreatography (ERCP) confirmed the existence of a short stenosis of the distal bile duct; therefore, following cytological examination, a 5-cm 10-Fr plastic stent was inserted. After 3 months, the patient was readmitted with jaundice. A second ERCP was carried out, revealing the earlier sphincterotomy but not the distal extreme of the stent in the papilla. Endoscopy showed that the stent had migrated proximally, and also revealed apparently neoplastic distal stenosis ( $\bullet$ Fig. 1 ).

Various attempts to retrieve the stent using a Dormia basket, balloon and foreign-body forceps were unsuccessful. The decision was made to insert a $10 \times 40$ covered self-expanding stent in order to enlarge the stenosis to facilitate further attempts at retrieval. The proximal end of the stent was positioned at the proximal edge of the stenosis ( $\bullet$ Fig. 2 ).

Finally, the migrated plastic stent was successfully and easily removed via the lumen of the metallic stent using rat-tooth forceps ( $\bullet$ Fig. 3).

The metallic stent was left in place in order to resolve the jaundice, as palliative treatment. There was a progressive im- provement in the patient's condition and bilirubin levels returned to normal limits in a few days.

To our knowledge, our technique has not been described previously and is relatively simple and safe. We believe it could be a feasible technique for retrieving proximally migrated plastic stents, particularly for cases in which more definitive palliative treatment is required.

\section{Endoscopy_UCTN_Code_TTT_1AR_2AZ}

\section{Competing interests: None}

M. T. Vázquez Rey, B. González Conde, P. A. Alonso Aguirre, I. Couto Wörner, E. Estévez Prieto, B. Crespo Suárez,

\section{A. Salazar Laya}

Department of Gastroenterology, La Coruña University Hospital Complex,

La Coruña, Spain

\section{References}

1 Katisnelos P, Kountouras J, Paroutoglou G et al. Migration of plastic biliary stents and endoscopic retrieval. Surg Laparosc Endosc Percutan Tech 2009; 19: 217-221

2 Chaurasia OP, Rauws EAJ, Fockens P et al. Endoscopic techniques for retrieval of proximally migrated biliary stents: the Amsterdam experience. Gastrointest Endosc 1999; 50: $780-785$

\section{Bibliography}

DOI $10.1055 / \mathrm{s}-0030-1256704$

Endoscopy 2011; 43: E376

(c) Georg Thieme Verlag KG Stuttgart · New York . ISSN 0013-726X

\section{Corresponding author}

\section{T. Vázquez Rey, MD}

Department of Gastroenterology

La Coruña University Hospital Complex

Xubias de Arriba 84

15006 La Coruña

Spain

Fax: +34-981-178364

Maria.Teresa.Vazquez.Rey@sergas.es

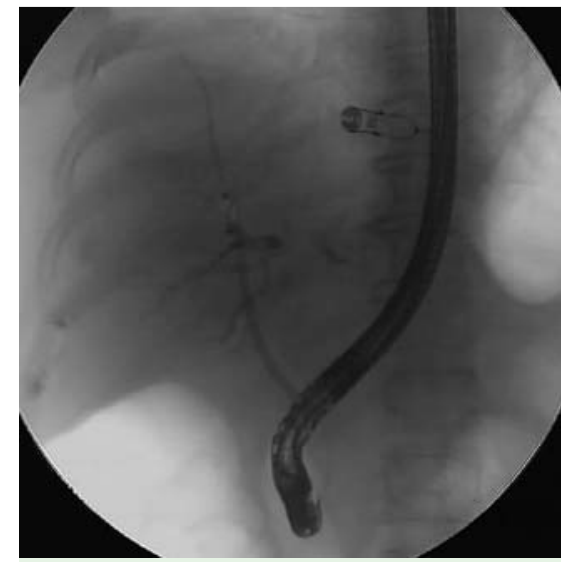

Fig. 1 Fluoroscopic image of the proximally migrated stent. The plastic stent was not visible at the papillary orifice because it was positioned within the biliary tree.

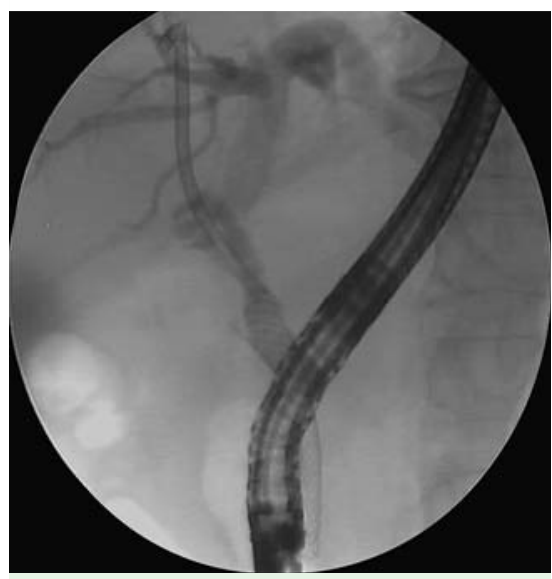

Fig. 2 A second covered self-expanding stent was inserted, and the plastic migrated one was removed through its lumen.

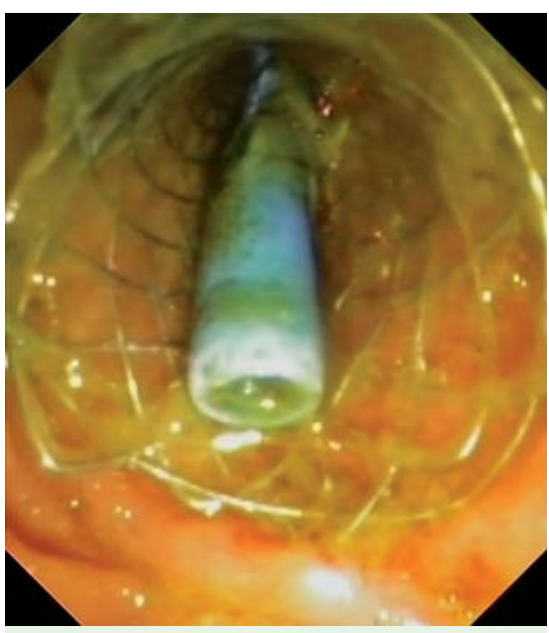

Fig. 3 Endoscopic image of the plastic stent appearing through the metallic stent lumen. 